This peer-reviewed published paper appears as: Del Carpio, M.R., Mosqueda, G., Lignos, D.G. (2019). "Experimental Investigation of Steel Building Gravity Framing Systems under Strong Earthquake Shaking", Soil Dynamics and Earthquake Engineering, Vol. 116, pp. 230-241, doi: 10.1016/j.soildyn.2018.10.017

\title{
EXPERIMENTAL INVESTIGATION OF STEEL BUILDING GRAVITY FRAMING SYSTEMS UNDER STRONG EARTHQUAKE SHAKING
}

\author{
Maikol Del Carpio R. ${ }^{1}$, Gilberto Mosqueda ${ }^{2}$, and Dimitrios G. Lignos ${ }^{3}$ \\ ${ }^{1}$ KPFF Consulting Engineers, Los Angeles, CA 90045, USA \\ ${ }^{2}$ Department of Structural Engineering, University of California, San Diego, CA 92093, USA \\ ${ }^{3}$ Deparment of Architecture, Civil and Environmental Engineering, Swiss Federal Institute of \\ Technology, Lausanne, Switzerland
}

\section{SUMMARY}

Hybrid simulations were conducted to evaluate the system-level seismic response of a 4-story steel moment frame building and its gravity framing system through various levels of ground motion shaking. The experimental substructure examined in detail corresponds to a half-scale $1 \frac{1}{2}$-bay by $1 \frac{1}{2}$-story subassembly of the steel gravity frame. Unlike typical beam-to-column connection tests, the subassembly, which represented typical gravity framing steel construction, captured the redistribution of force demands in beams, columns, panel zones, and the composite floor slab while exhibiting inelastic behavior. Horizontal as well as varying vertical forces were applied on the test specimen to mimic realistic boundary and loading conditions. This paper focuses on the experimental response of the gravity framing system and its contribution to the lateral resistance of a steel frame building. In particular, the lateral resistance and failure mechanisms of the test frame are described and compared to numerical simulations based on state-of-the-art modeling approaches. The data generated from these experiments provides valuable insight on gravity frame behavior towards improvement and verification of frame models at the system level.

Keywords: gravity framing system, force-redistribution, seismic performance, hybrid simulation, collapse, destabilizing effects

\section{INTRODUCTION}

Secondary systems such as the gravity-force-resisting system (or simply "gravity frames") in steel frame buildings are commonly neglected in the seismic performance assessment of buildings. Instead, the primary lateral load-resisting system is only considered for this purpose. The gravity framing connections are designed to carry gravity loads only and consequently assumed to provide minimal lateral resistance. Cyclic testing of typical shear-tab beam-to-column connections (e.g., [1-3]) underscore that there is appreciable reserve capacity in these connections. Following on these experimental studies, only limited numerical studies have been conducted to assess the influence of the gravity-framing system on the seismic response of frame buildings [4-6].

While most large-scale subassembly tests conducted to date conveniently obtain information on single structural components, they do not necessarily capture the redistribution of forces within a frame once earthquake induced damage occurs. Another limiting feature entails the fact that prescribed loading protocols have been routinely used in such tests [7]. The majority of these protocols are symmetric [8]. Shake table collapse tests [9-10] suggest that the hysteretic behavior of systems may be vastly different than that obtained from component tests subjected to predefined symmetric cyclic loading histories. The aforementioned findings highlight the need for 
This peer-reviewed published paper appears as: Del Carpio, M.R., Mosqueda, G., Lignos, D.G. (2019). "Experimental Investigation of Steel Building Gravity Framing Systems under Strong Earthquake Shaking", Soil Dynamics and Earthquake Engineering, Vol. 116, pp. 230-241, doi: 10.1016/j.soildyn.2018.10.017

more physical system or subsystem tests with more realistic loading histories. However, the associated financial constraints may be a compelling issue in this case.

Hybrid simulation with substructuring has been employed as a cost-efficient alternative to largescale system-level testing of frame structures [11-14]. In this approach, only key subassemblies are tested in the laboratory (i.e., physical substructures) while the rest of the structure is modeled numerically (i.e., numerical substructures), both interacting to simulate the response of the full system. Hashemi and Mosqueda [15] presented and validated a substructuring technique for hybrid simulation of multi-story frame structures. This approach was adopted to test two large-scale realistic subassemblies of a steel moment resisting frame (MRF) and a gravity frame at the University at Buffalo [16]. The details of the implementation of the hybrid simulation algorithms and the steel MRF are discussed in Del Carpio et al. [17] and Del Carpio et al. [11], respectively.

This paper focuses on the seismic performance of a steel gravity framing substructure as well as the effectiveness of numerical modeling tools in simulating the response of the test structure from the onset of damage through various seismic intensities of interest to the engineering profession. The $1 \frac{1}{2}$-bay by $1 \frac{1}{2}$-story subassembly with composite floor slab examined here demonstrates the damage progression in the gravity (shear-tab) beam-to-column connections and redistribution of force demands within the beams, columns, panel zones, and the composite floor slab in the inelastic range of behavior.

\section{PROTOTYPE BUILDING}

The four-story office building shown in Figure 1, designed and evaluated by Lignos and Krawinkler [18] was selected as the prototype building. This Category II (importance factor equal to 1.0) building was designed for a site in Los Angeles, CA according to the U.S. codes/standards of practice at that time [19-21]. The lateral load-resisting system consisted of steel special moment frames (located around the perimeter of the building) with fully restrained reduced beam sections (RBS) in both loading directions. The location of the moment connections is indicated by a solid triangle symbol in Figure 1. The interior frames shown in Figure 1 were part of the gravity framing system in which the beams and columns were connected through conventional shear-tab beam-tocolumn connections indicated by the solid circle symbol.

An elevation view of the three-bay gravity frame selected for hybrid testing is shown in Figure 1(b). The story heights of the four-story building were interpreted as top-of-slab dimensions. Lignos et al. [9] and Hashemi and Mosqueda [15] examined the behavior of the two-bay steel moment resisting frame (MRF) in the orthogonal direction in shake table and hybrid simulation studies, respectively. In the aforementioned studies a $1 / 8$-scale model of the two-bay frame was employed. The interior frames shown in Figure 1(a) represent the gravity framing system tested as part of the present experimental program. Details of the entire testing program including the results of the moment frames are presented in detail in Del Carpio et al. [16]. 
This peer-reviewed published paper appears as: Del Carpio, M.R., Mosqueda, G., Lignos, D.G. (2019). "Experimental Investigation of Steel Building Gravity Framing Systems under Strong Earthquake Shaking", Soil Dynamics and Earthquake Engineering, Vol. 116, pp. 230-241, doi: 10.1016/j.soildyn.2018.10.017

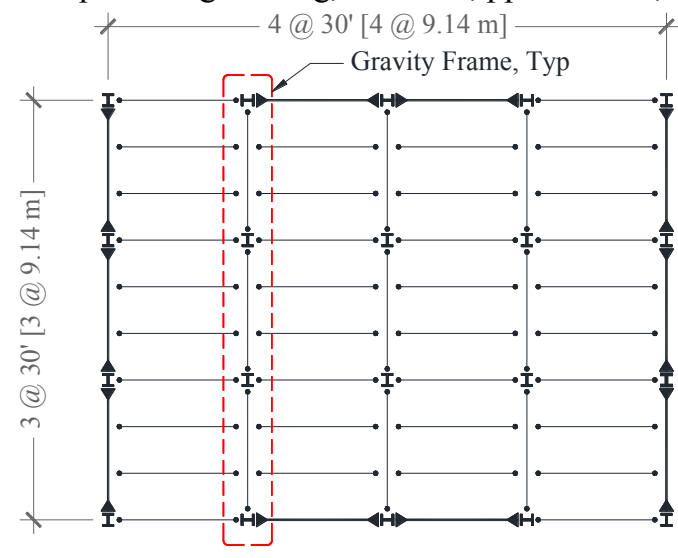

(a) Typical floor plan

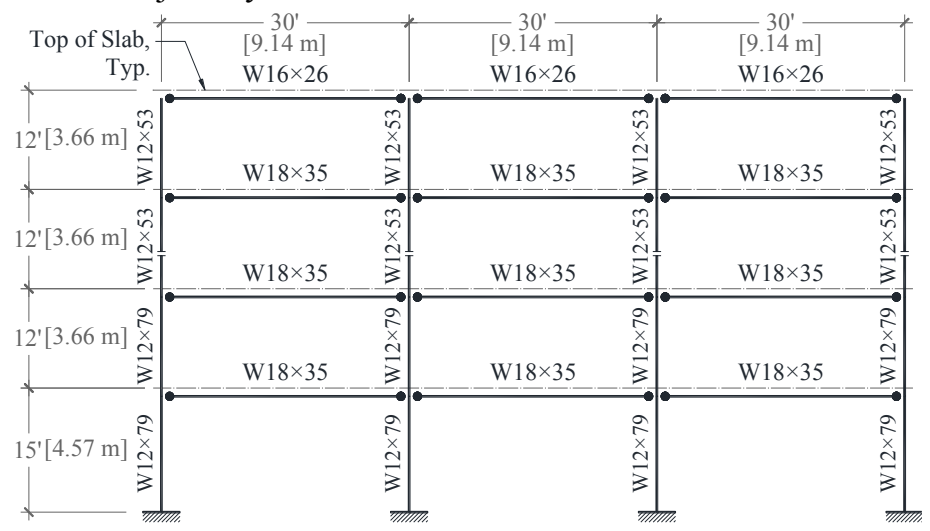

(b) Elevation of gravity frame selected for testing

Figure 1 Prototype office building used as part of the experimental program

\section{TEST SPECIMEN AND EXPERIMENTAL PROCEDURE}

A $1 \frac{1}{2}$-bay by $1 \frac{1}{2}$-story subassembly of the gravity frame shown in Figure 1(b) was tested in the laboratory via hybrid simulation with substructuring. The substructuring technique developed by Hashemi and Mosqueda [15] was applied here to a large-scale realistic structural model. These previous studies validated the substructuring technique through a series of hybrid simulations on a 1/8-scale aluminum frame structure previously tested on a shake table by Lignos et al. [9]. In the substructuring approach, the boundary conditions of the physical substructure were simplified with physical hinges at the mid-span of beams and columns similar to conventional cruciform or Tshaped subassemblies. This simplification is necessary to test larger frame subassemblies using a reduced number of actuators without having to control rotational degrees of freedom at boundaries. However, the substructuring technique implemented here minimizes the loss of simulation accuracy due to the simplified boundary conditions by providing an overlapping domain between the physical and numerical substructures. As an extension to this method, the column axial forces from gravity loading were considered during the hybrid testing presented here. Numerical studies demonstrating the substructuring technique for the frame examined here are provided in Del Carpio et al. [17]. For the hybrid simulation, the numerical substructure was modeled in the Open System for Earthquake Engineering Simulation (OpenSees) [22] and was integrated with the physical substructure via the Open-Source Framework for Experimental Setup and Control (OpenFresco) [23]. Previous assessments of numerical and experimental errors provided insight to key parameters of the hybrid simulation integration algorithms and actuator control system towards achieving reliable results [24-25].

\subsection{Hybrid Model of Steel Moment-Resisting Frame and Gravity Frame}

Figure 2 shows a schematic elevation of the half-scale hybrid model developed to simulate the response of the steel MRF building with gravity framing. The physical and numerical substructures are indicated in the figure. Note that the model accounts for the two MRF and three gravity frames in the prototype building. The hybrid model includes a detailed gravity frame model with a physical substructure, all coupled with a fully-numerical model of the steel MRF. Acknowledging that the contribution of the gravity frames is a function of the orientation of the gravity columns 
This peer-reviewed published paper appears as: Del Carpio, M.R., Mosqueda, G., Lignos, D.G. (2019). "Experimental Investigation of Steel Building Gravity Framing Systems under Strong Earthquake Shaking", Soil Dynamics and Earthquake Engineering, Vol. 116, pp. 230-241, doi: 10.1016/j.soildyn.2018.10.017

[4], the hybrid model of the gravity frame here was developed assuming that all gravity columns seen in Figure 1(a), are of the same size, they are continuous and oriented with their strong axis in the direction of lateral loading.

The experimental substructure representing half of the first story level was primarily selected to examine the response of a first story frame with the connecting beams and columns extend by half of their length to realistically approximate the corresponding boundary conditions. The dashed lines indicate the substructures' boundaries. The numerical model extends to overlap with the physical substructure as part of the implemented substructuring strategy. The hysteretic response of the two joints within the overlapping domain can be compared to evaluate the predicted and measured response. The physical and numerical components of the hybrid model were scaled by a length scale factor of $S=0.50$. As such, the ground motion time step was compressed by the time scale factor of $S^{1 / 2}=0.707$ based on similitude laws for true-replica physical models [26].

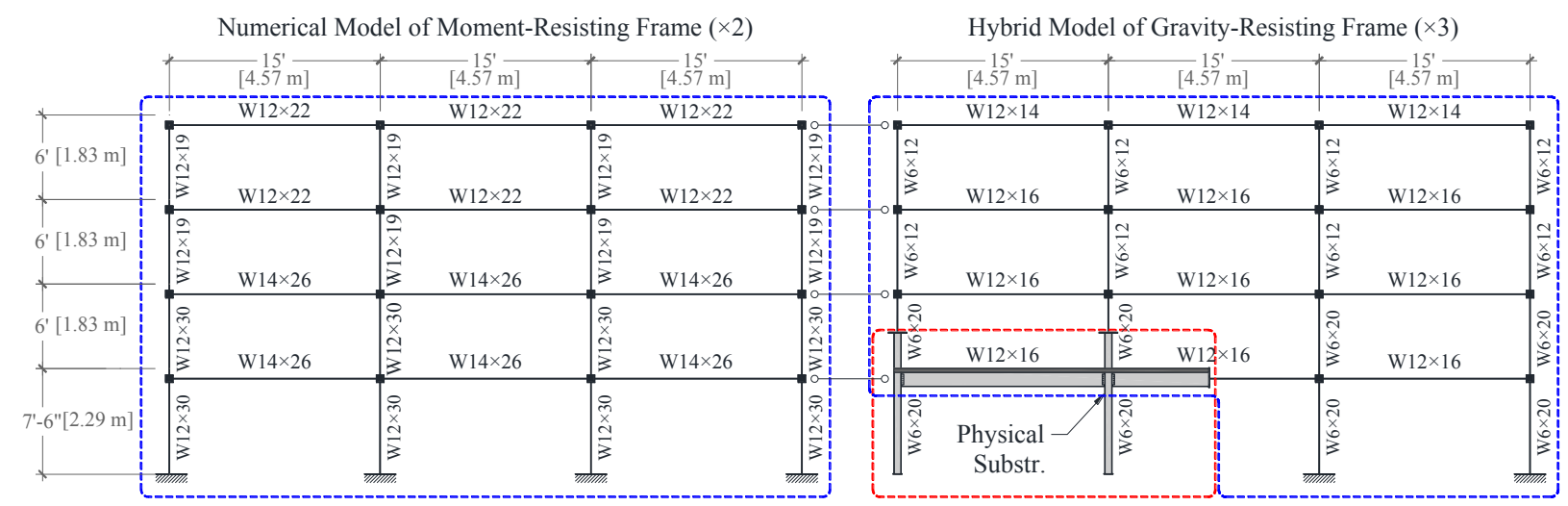

Figure 2 Schematic elevation of hybrid model of the steel frame

The wide-flange sections of the half-scale hybrid model, labeled in Figure 2, were selected to match relevant target section geometric properties such as the moment of inertia $\left(I_{x}\right)$, the crosssectional area $(A)$, the plastic modulus $\left(Z_{x}\right)$, and the local flange and web slenderness ratios, $b_{f} / 2 t_{f}$, $h / t_{w}$, respectively, as defined in the AISC-341-16 [27] provisions. These geometric parameters strongly influence the deterioration characteristics of commonly used wide-flange sections [28].

\subsubsection{Design and Construction of Test Specimen (Physical Substructure)}

The test specimen shown in Figure 3 was designed and constructed to retain many of the features of realistic full-scale frame structures. The W12 $\times 16$ floor beams were connected to the W6 $\times 20$ columns with conventional single row shear-tab beam-to-column connections representing typical gravity connections. The composite floor slab consisted of light-weight concrete with a specified strength of $20 \mathrm{MPa}(3000 \mathrm{psi})$ at 28 days and a maximum aggregate size of $13 \mathrm{~mm}(1 / 2 \mathrm{in})$ poured over a 20GA metal deck (deck type B by Vulcraft). The total thickness of the floor slab was specified as $83 \mathrm{~mm}\left(3^{1 / 4} \mathrm{in}\right)$ [depth of metal deck $=38 \mathrm{~mm}\left(1 \frac{1}{2} \mathrm{in}\right)$, thickness of concrete slab above deck $\left.=44 \mathrm{~mm}\left(1 \frac{3}{4} \mathrm{in}\right)\right]$. The floor slab was reinforced with a welded wire mesh $[6 \times 6-$ $\mathrm{W} 1.4 \times \mathrm{W} 1.4$ - wires spaced at $152 \mathrm{~mm}(6 \mathrm{in})$ with a total steel area of $59 \mathrm{~mm}^{2}$ per meter in both directions] placed over the entire area of the floor slab and reinforcing bars with a diameter of 9.5 $\mathrm{mm}$ (\#3 bars) across the girder for crack control due to gravity loading. Shear studs were provided 
This peer-reviewed published paper appears as: Del Carpio, M.R., Mosqueda, G., Lignos, D.G. (2019). "Experimental Investigation of Steel Building Gravity Framing Systems under Strong Earthquake Shaking", Soil Dynamics and Earthquake Engineering, Vol. 116, pp. 230-241, doi: 10.1016/j.soildyn.2018.10.017

along the girder at $152 \mathrm{~mm}$ (6 in) on center and the floor beams at each metal deck rib. The floor slab was constructed to extend out $610 \mathrm{~mm}(2 \mathrm{ft})$ on both sides of the beam to maintain symmetry and minimize any potential out-of-plane response during testing. The total width of the concrete slab was selected to match the corresponding effective width as per AISC [27] for an internal gravity framing beam. The floor beams support the weight of the floor slab and the steel plates used to simulate gravity loads on the test specimen. As shown in Figure 3, an HSS $6 \times 6 \times 1 / 2$ loading beam was used to transfer the load from the horizontal actuator to the test specimen. The loading mechanism is further discussed in a subsequent section.

Details of the shear-tab connection of the half-scale gravity frame physical subassembly are shown in Figure 4(b). The connection geometry is half of that of the full-scale connection except for the $12 \mathrm{~mm}$ (1/2 in) diameter bolts. A complete set of drawings is available in Del Carpio et al. [16]. Except for the A36 (i.e., $F y=235 \mathrm{MPa}$ ) steel $5 \mathrm{~mm}(3 / 16$ in) shear-tab plate used in the simple gravity connections, wide-flange sections and steel plates (continuity plates, shear-tab plates, doubler plates, etc.) were fabricated from A572 Grade 50 (i.e., $F_{y}=345 \mathrm{MPa}$ ) steel. The test specimen utilized simple base plate connection details that reflected the current design practice. In brief, the base plate had a thickness of $13 \mathrm{~mm}$ (1/2 in) and four bolts (ASTM A325) of $13 \mathrm{~mm}(1 / 2$ in) diameter. Although these simple connections are commonly assumed as pinned, they are characterized by an appreciable level of flexibility [29] that was confirmed by measurements in this experimental program.

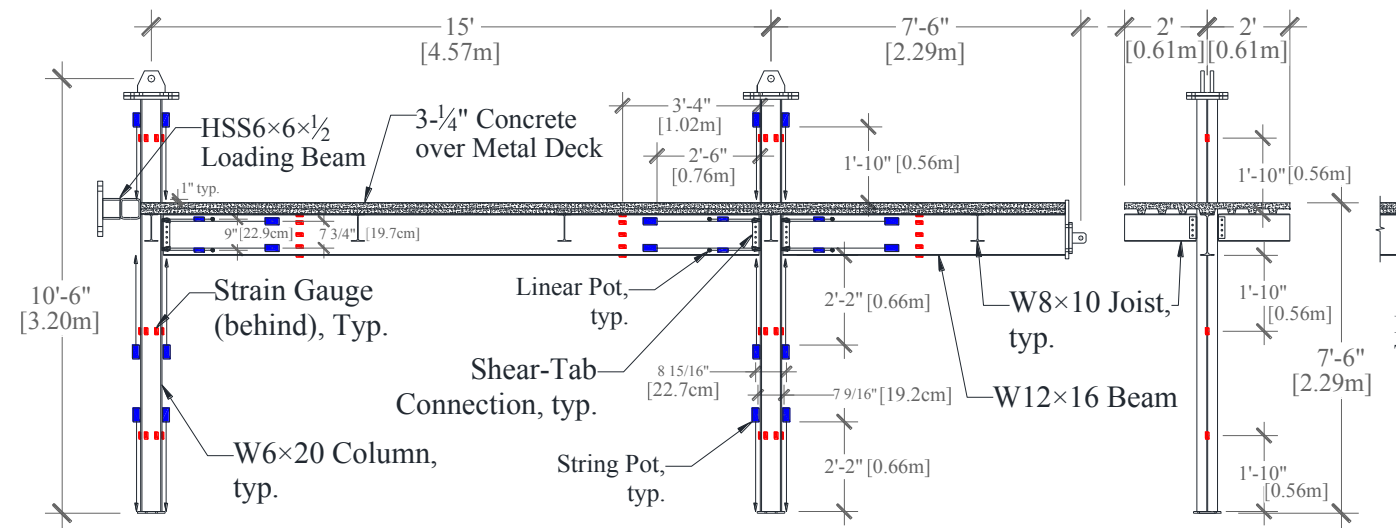

(a) Elevation (b) Section

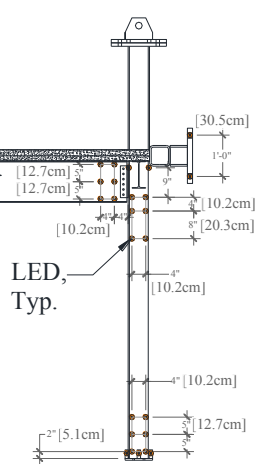

(c) LEDs

Figure 3 Test specimen and instrumentation 
This peer-reviewed published paper appears as: Del Carpio, M.R., Mosqueda, G., Lignos, D.G. (2019). "Experimental Investigation of Steel Building Gravity Framing Systems under Strong Earthquake Shaking", Soil Dynamics and Earthquake Engineering, Vol. 116, pp. 230-241, doi: 10.1016/j.soildyn.2018.10.017

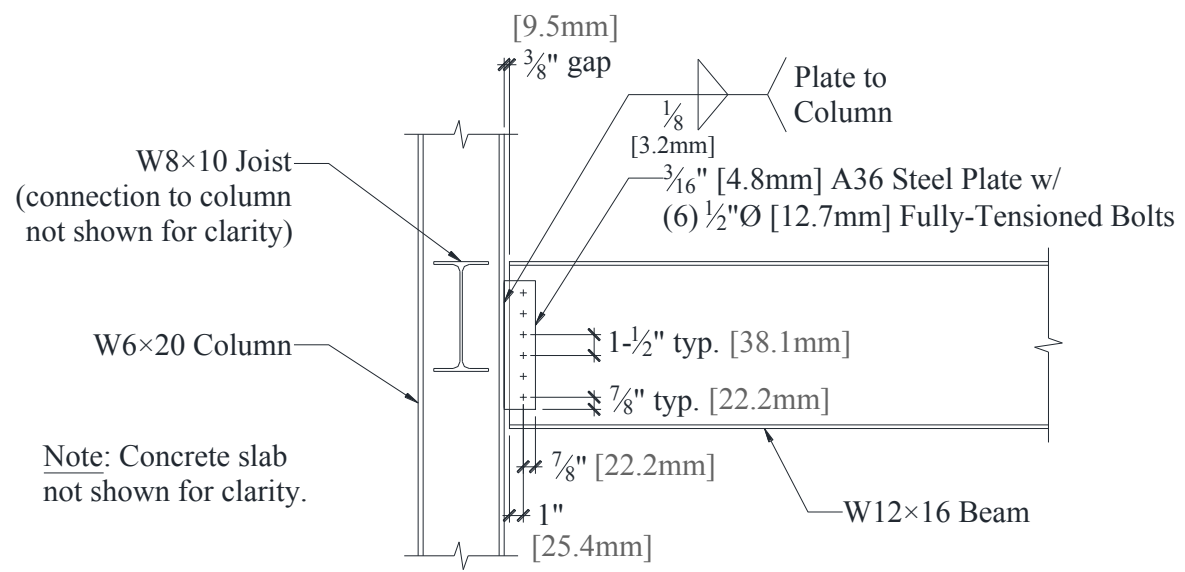

(a) Side view of shear-tab connection

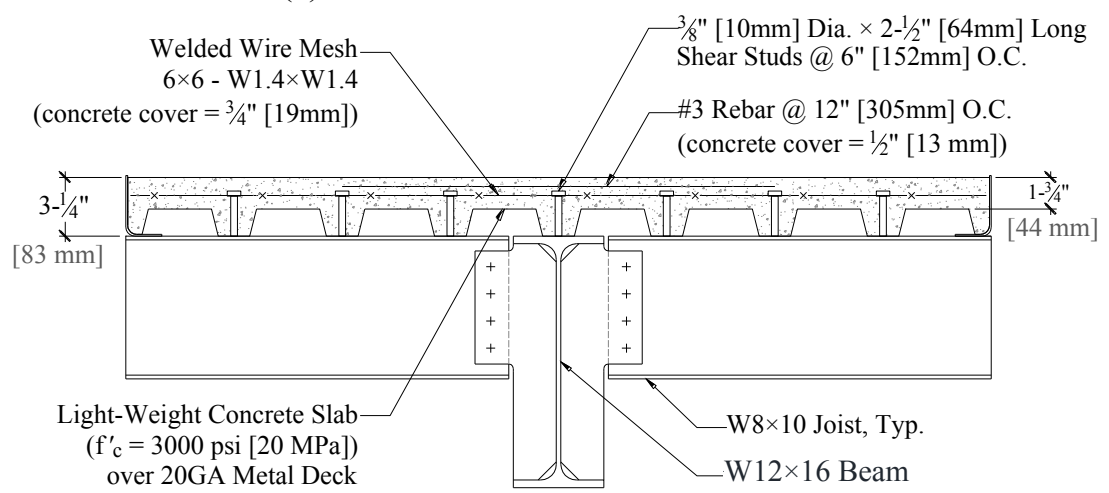

(b) Cross section of composite floor slab

Table 1 summarizes the measured yield $\left(F_{y}\right)$ and ultimate $\left(F_{u}\right)$ stresses of steel coupons for the $\mathrm{W} 12 \times 16$ beam, W6 $\times 12$ column and $5 \mathrm{~mm}(3 / 16 \mathrm{in})$ shear-tab plate at an offset strain of $0.2 \%$. The average yield stress values for the $\mathrm{W} 12 \times 16$ and $\mathrm{W} 6 \times 20$ coupons were $338 \mathrm{MPa}(49 \mathrm{ksi})$ and $365 \mathrm{MPa}(53 \mathrm{ksi})$, respectively. In order to measure the concrete slab properties, four concrete cylinders were tested; two of them were tested at 28 days and the remaining ones on the day of hybrid testing (at 51 days). Table 1 also lists the results from the concrete cylinder tests. The compressive strength of cylinder \#1 was not obtained due to malfunctioning instrumentation.

Table 1 Measured material properties for steel cross sections and concrete slab

\begin{tabular}{|c|c|c|c|c|c|c|c|c|c|c|}
\hline $\begin{array}{c}\text { Coupon/ } \\
\begin{array}{c}\text { Specimen } \\
\text { No }\end{array}\end{array}$ & \multicolumn{3}{|c|}{ W12 $\times 16$ Beam } & \multicolumn{3}{c|}{ W6 $\times 20$ Column } & \multicolumn{2}{c|}{ A36 Steel Plate } & \multicolumn{2}{c|}{ Concrete Slab } \\
\cline { 2 - 11 } & $\begin{array}{c}F_{y} \\
{[\mathrm{MPa}]}\end{array}$ & $\begin{array}{c}F_{u} \\
{[\mathrm{MPa}]}\end{array}$ & Loc. & $\begin{array}{c}F_{y} \\
{[\mathrm{MPa}]}\end{array}$ & $\begin{array}{c}F_{u} \\
{[\mathrm{MPa}]}\end{array}$ & $\begin{array}{c}F_{y} \\
{[\mathrm{MPa}]}\end{array}$ & $\begin{array}{c}F_{y} \\
{[\mathrm{MPa}]}\end{array}$ & $\begin{array}{c}\text { Cyl. Age } \\
{[\text { days }]}\end{array}$ & $\begin{array}{c}f_{c}^{\prime} \\
{[\mathrm{MPa}]}\end{array}$ \\
\hline 1 & Web & 345.4 & 435.1 & Web & 364.0 & 451.6 & 413.0 & 464.0 & 28 & NA \\
\hline 2 & Web & 366.5 & 426.1 & Web & 376.5 & 453.0 & 415.8 & 465.4 & 28 & 22.5 \\
\hline 3 & Flange & 328.2 & 424.7 & Flange & 361.3 & 449.5 & - & - & 51 & 25.3 \\
\hline 4 & Flange & 333.7 & 426.8 & Flange & 365.4 & 448.8 & - & - & 51 & 25.9 \\
\hline
\end{tabular}


This peer-reviewed published paper appears as: Del Carpio, M.R., Mosqueda, G., Lignos, D.G. (2019). “Experimental Investigation of Steel Building Gravity Framing Systems under Strong Earthquake Shaking", Soil Dynamics and Earthquake Engineering, Vol. 116, pp. 230-241, doi: 10.1016/j.soildyn.2018.10.017

169 The numerical substructures including the MRF and the rest of the gravity framing were modeled 170 in OpenSees using a concentrated plasticity approach. The inelastic moment-rotation response of the shear-tab connections was simulated with the hysteretic model developed by Lowes and Altoontash [30] and modified by Mitra [31]. This model was calibrated to test data on conventional shear tab beam-to-column connections [1]. To account for potential nonlinearity in beams and columns of the gravity framing system, nonlinear plastic hinge elements using the hysteretic model by Lignos and Krawinkler [28] were considered. The potential panel zone inelastic shear distortion was considered with the Krawinkler model [4]. Geometric nonlinearities were included using the P-Delta formulation in OpenSees. The numerical substructure included flexible supports that matched the experimentally measured column base flexibility of the physical substructure. To account for the ratio of number of moment to gravity frames in the direction of loading, the numerical model of the moment frame shown in Figure 2(b) was encapsulated in a separate OpenSees model as a second numerical substructure. This substructure was coupled with the gravity frame model via OpenFresco. Thus, the force feedback vector returned from the moment frame numerical substructure to the integration algorithm was modified by $2 / 3$ (ratio of moment to gravity frames). In this coupling procedure, the lateral displacements of the floor diaphragms for the moment and gravity frames were constrained at each level. Viscous damping was considered using the Rayleigh damping model based on the approach discussed in Zareian and Medina [32]. A damping ratio of $2.0 \%$ was assigned to the first two natural frequencies of the steel

188 MRF.

The hybrid simulations were conducted with the modified implicit Newmark method with constant number of iterations [34-35] as implemented in OpenSees [36]. The complexity of the numerical model required the use of an integration time step as small as $0.00117 \mathrm{~s}$ with eight iterations for the higher intensity ground motion shaking. The accuracy and stability of the integration parameters for the hybrid model were evaluated by comparison to the conventional numerical model used for the pre-test predictions [17].

\subsection{Instrumentation of the Test Specimen}

\subsubsection{Uniaxial Strain Gauges}

197 A total of thirty-nine uniaxial strain gages were strategically placed on the steel components of the

198 test specimen as shown in Figure 3(a) to compute the distribution of bending moment and axial 199 load demands along the steel beams and columns. The strain gauges were grouped at different 200 plane girder and column cross sections so as the flexural and axial demands could be computed by assuming linear extrapolation of the corresponding force demands. Member forces were also estimated at girder sections with composite slab by joint equilibrium with column moments while neglecting the interaction with the shear force. For the internal joint with two composite beams, the moment in the extended half-beam was determined from the axial force on the vertical link member. For the hybrid model, the shear and moment at the top end of the first story columns was returned as feedback forces from the experimental substructure. It is noteworthy that measurements of the instrumentation system were set to zero at the beginning of the hybrid simulations. The moments and rotations of the physical substructure presented later do not include initial values from gravity loading of the physical subassembly from dead weight. 
This peer-reviewed published paper appears as: Del Carpio, M.R., Mosqueda, G., Lignos, D.G. (2019). "Experimental Investigation of Steel Building Gravity Framing Systems under Strong Earthquake Shaking", Soil Dynamics and Earthquake Engineering, Vol. 116, pp. 230-241, doi: 10.1016/j.soildyn.2018.10.017

211 Figure 3 shows 18 string displacement potentiometers (string pots) and six linear displacement 212 potentiometers (linear pots) installed on the test specimen to measure chord rotations over shear213 tab connections columns and girders as well as panel zone shear distortions. Rotations were measured over a length of $660 \mathrm{~mm}$ ( $26 \mathrm{in}$ ) for columns and $762 \mathrm{~mm}$ (30 in) for beams as shown in Figure 3. Four additional string pots, not shown in Figure 3, were used to measure the out-of-plane response of the test specimen (one string pot was attached at each joint of the test specimen) and the relative displacement of the two horizontal actuators with respect to the ground floor (one string pot was placed at the head of each horizontal actuator).

\subsubsection{Krypton Coordinate Tracking System}

A total of twenty-five light-emitting diodes (LEDs) were attached at different locations around the end column of the test specimen as shown in Figure 3. The Krypton System was used to track the three-dimensional position of LEDs through infrared cameras. Due to field of view limitations of the camera system, LEDs could not be placed around the entire physical test specimen. The arrangement of LEDs shown in Figure 3(c) permitted obtaining localized rotations over a sheartab connection, beam and column ends, as well as the shear distortion of the end column panel zone. The deformation demands of the end column base plate were also obtained with the same system. This dense instrumentation captures the distribution of deformations throughout the frame subassembly and can be used to more closely assess numerical models.

\subsection{Loading Frame}

The experimental setup shown in Figure 5 was designed to apply lateral as well as vertical loads on the test specimen during a hybrid simulation. The test specimen was mounted on the strong floor using two interface $274.3 \times 152.4 \times 3.8 \mathrm{~cm}\left(9^{\prime} \times 5^{\prime} \times 1^{1} / 2\right.$ ") steel plates. These base plates added flexibility at the column supports, with an equivalent rotational stiffness quantified with measurements from the Krypton system. Lateral loading was applied through two horizontal actuators controlling the lateral displacements at the first and mid-second story levels of the physical substructure. The horizontal link member transferred the lateral loads from the top horizontal actuator to the top of the physical substructure columns connected by pins. The bottom horizontal actuator was connected to the floor level of the test specimen through a HSS6 $6 \times 6 \times 1 / 2$ loading beam (see also Figure 3). This loading beam was welded to the end column and anchored to the floor slab using 4 steel rods embedded in the concrete slab (the steel rods were placed at least $305 \mathrm{~mm}$ (12 in.) away from the center line of the beam to avoid strengthening the connection). Although the latter connection aimed at transferring part of the lateral loads through the slab (more similar to the actual load path in reality), the more direct load path and higher stiffness of the welded connection likely transferred most of the lateral load directly to the end column. This load was then transferred through the beam as an axial force to the other column. This load path is somewhat different to that of a realistic gravity frame system where the floor inertial forces are transferred to the frame via collector beams. This should be considered for future studies to properly assess the influence of composite action on the behavior of steel frame buildings.

Gravity loads at the elevated first floor level of the physical substructures were simulated by four $37.8-\mathrm{kN}$ (8.5-kip) steel plates. These were placed on the gravity frame physical substructure to 
This peer-reviewed published paper appears as: Del Carpio, M.R., Mosqueda, G., Lignos, D.G. (2019). "Experimental Investigation of Steel Building Gravity Framing Systems under Strong Earthquake Shaking", Soil Dynamics and Earthquake Engineering, Vol. 116, pp. 230-241, doi: 10.1016/j.soildyn.2018.10.017 simulate a uniformly distributed dead load of $4.3 \mathrm{kPa}$ [90 pound per square foot (psf)] and 25\% of the code-specified live load of $2.4 \mathrm{kPa}$ (50 psf). Additional gravity loads on the columns of the physical substructure from upper stories were applied with two vertical actuators. A reaction frame for these vertical actuators was mounted on top of the support frame. A vertical guide connection was devised between the reaction frame and horizontal link member. It consisted of a vertical steel pipe (connected to the horizontal link member at the bottom) freely sliding inside an outer pipe (connected to the reaction frame at the top and braced to maintain a right angle). This connection provided horizontal coupling between the reaction frame and the horizontal link member without transferring vertical forces. This helped to maintain a vertical alignment of the force-controlled actuators (mounted between these two members) and to accommodate the actuator vertical displacements.

A support frame surrounded the physical substructure to provided out-of-plane support and serve as a reaction frame for vertical actuators. The various components of the test setup (support frame, reaction frame, and horizontal and vertical link members) were connected through clevises so that, under the application of lateral loads, the supporting frame swayed and guided the physical substructure in the direction of loading providing minimal lateral resistance. Clevises at the top of the columns of the test specimen and end of cantilevered beam were provided to simplify the boundary conditions at the interface with the numerical substructure. The cantilever portion of the first-story girder was underpinned using a vertical link member (with clevises at the top and bottom) to limit vertical deflection at the tip and generate lateral displacement dependent forces at the fixed joint. Rotations and moments at the boundaries were not fully enforced since they are difficult to apply with linear hydraulic actuators. However, these simplified boundary conditions with overlapping domain were part of the substructuring strategy to apply equivalent forces at the joints [17].

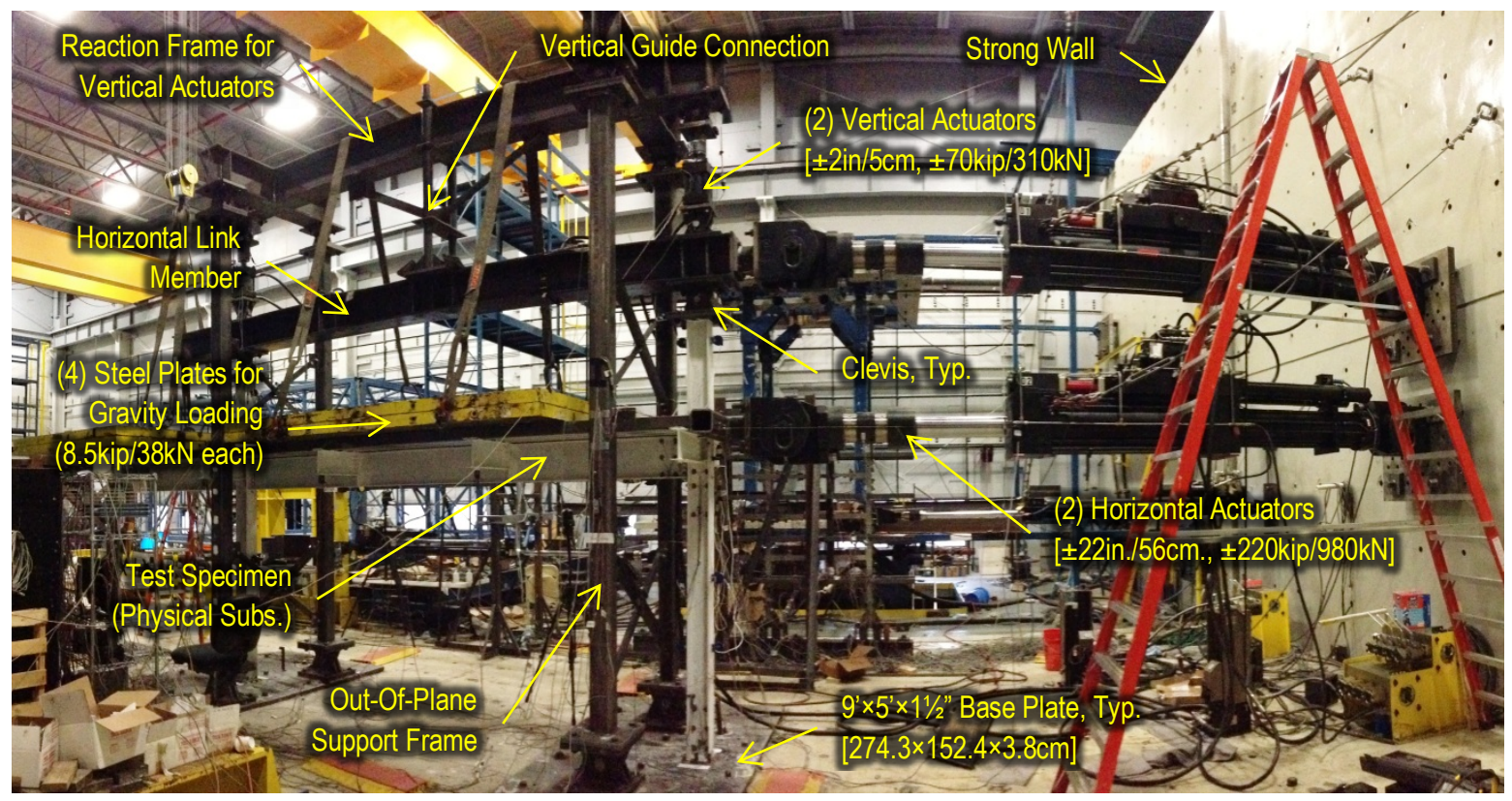


This peer-reviewed published paper appears as: Del Carpio, M.R., Mosqueda, G., Lignos, D.G. (2019). "Experimental Investigation of Steel Building Gravity Framing Systems under Strong Earthquake Shaking", Soil Dynamics and Earthquake Engineering, Vol. 116, pp. 230-241, doi: 10.1016/j.soildyn.2018.10.017

\subsection{Loading Protocol}

The hybrid model was subjected sequentially to four increasing intensities of the 1989 Loma Prieta ground motion recorded at Los Gatos Presentation Center (LGPC) station. The ground motion amplitude was scaled to $25 \%, 100 \%, 150 \%$, and $200 \%$. The unscaled response spectra of the selected earthquake record matched approximately the maximum considered earthquake (MCE) at the fundamental period of the prototype steel frame building in the loading direction of interest. The $150 \%$ and $200 \%$ seismic events represent low-probability of occurrence seismic events that could potentially trigger earthquake-induced collapse.

\section{EXPERIMENTAL RESULTS}

The hybrid simulations generated insight into the behavior of the tested gravity frame subassembly revealing that damage was mainly concentrated at the shear-tab connections with minimal yielding on the structural beams and columns. The shear-tab connections sustained large rotation demands (up to $0.10 \mathrm{rad}$.) while maintaining their vertical load carrying capacity. These observations are consistent with prior findings regarding the cyclic behavior of gravity connections [1].

Table 2 summarizes the testing sequence and provides the corresponding peak roof and story drift ratio demands of the hybrid model for reference. Figure 6 shows the first story drift history resulting from the four hybrid simulation experiments. The pre-test numerical predictions are shown in the same figure for comparison purposes. The global response of the hybrid model compared favorably with numerical pre-test predictions including through the high intensity ground motions. The column base flexibility was experimentally measured prior to testing and accounted for in the numerical substructure of the hybrid model and numerical pre-test predictions. While the shear force contribution of the physical substructure representing the gravity frame to the response of the complete frame system is small, the correlation to pre-test numerical simulations indicate that reliable results were obtained from the hybrid simulation.

Table 2 Summary of peak roof and story drift ratios for hybrid simulation tests

\begin{tabular}{|c|c|c|c|c|c|c|c|}
\hline \multirow{2}{*}{ Test ID } & \multirow{2}{*}{$\begin{array}{c}\text { Simulation } \\
\text { Duration }\end{array}$} & \multirow{2}{*}{$\begin{array}{c}\text { Actual } \\
\text { Time } \\
\end{array}$} & Duration & \multirow{2}{*}{$\begin{array}{c}\text { Peak Roof } \\
\text { Drift Ratio } \\
{[\%]}\end{array}$} & \multicolumn{4}{|c|}{ Peak Story Drift Ratios [\%] } \\
\cline { 5 - 8 } & & $1^{\text {st }}$ Story & $2^{\text {nd }}$ Story & $3^{\text {rd }}$ Story & $4^{\text {th }}$ Story \\
\hline HS02-25\% & $16.2 \mathrm{~s}$ & $3 \mathrm{~h}: 22 \mathrm{~m}$ & +0.6 & +0.7 & +0.6 & +0.6 & +0.4 \\
\hline HS02-100\% & $16.2 \mathrm{~s}$ & $2 \mathrm{~h}: 48 \mathrm{~m}$ & -1.7 & -2.0 & -2.2 & -1.8 & -1.1 \\
\hline HS02-160\% & $16.2 \mathrm{~s}$ & $2 \mathrm{~h}: 48 \mathrm{~m}$ & -2.5 & -3.1 & -3.3 & -2.4 & -1.2 \\
\hline HS02-200\% & $16.2 \mathrm{~s}$ & $3 \mathrm{~h}: 22 \mathrm{~m}$ & -6.5 & -7.8 & -9.1 & -7.8 & -1.4 \\
\hline
\end{tabular}

The physical substructure being part of the gravity frame was expected to have a minor contribution to the total lateral resistance of the frame. However, there was a noticeable difference in the residual deformation at the end of the hybrid simulation test series that mainly occurred during the $200 \%$ scaled seismic intensity. This is attributed to residual deformations accumulated from previous seismic intensities that are very sensitive to various modeling parameters [37]. The influence of numerical models representing the shear-tab beam-to-column connections, steel beams, columns and panel zones is examined in more detail in the subsequent sections. 
This peer-reviewed published paper appears as: Del Carpio, M.R., Mosqueda, G., Lignos, D.G. (2019). "Experimental Investigation of Steel Building Gravity Framing Systems under Strong Earthquake Shaking", Soil Dynamics and Earthquake Engineering, Vol. 116, pp. 230-241, doi: 10.1016/j.soildyn.2018.10.017

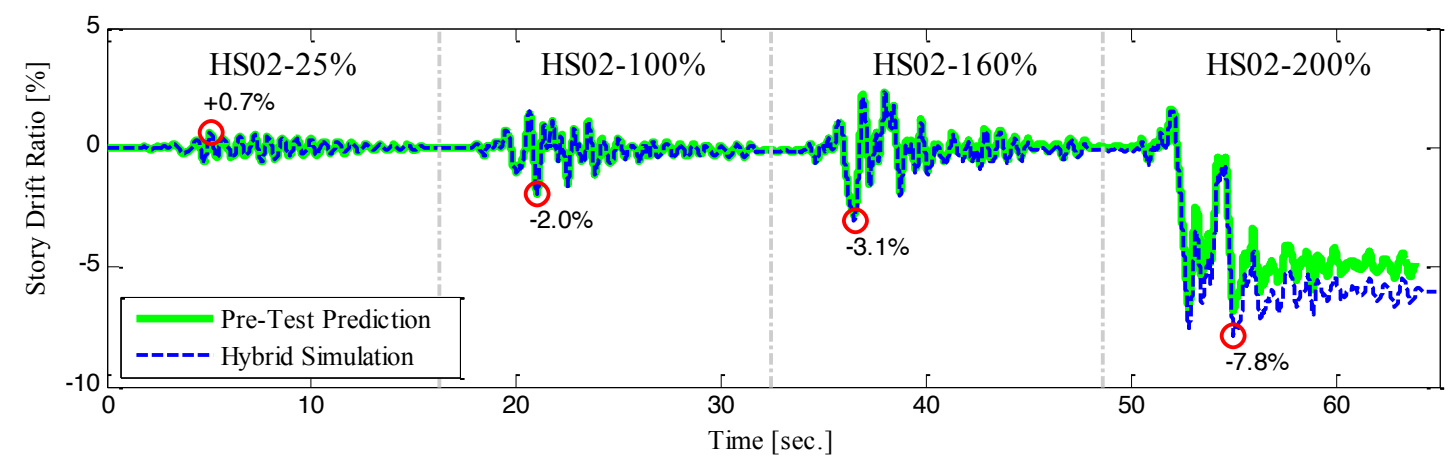

Figure 6 First story drift ratio history resulting from hybrid simulations

\subsection{Hysteretic Behavior of Shear-Tab Beam-to-Column Connections}

Figure 7 shows the deduced moment-rotation relation and Figure 8 shows the corresponding photographs of the damage state of shear-tab connection A of the physical substructure. The location of the shear-tab connections, designated as shear-tab connection " $A$ ", B" and "C", is indicated with a sketch right above Figure 7. The shear-tab connections of the physical substructure are located within the overlapping domain. As such, the numerical model includes the simulated response of the same shear-tab connection and provide a basis for comparisons. The difference in strength and stiffness combined with the substructuring technique resulted in a redistribution of force demands within experimental and numerical joints, as is evident at higher seismic intensities. The peak inelastic rotation demands are indicated in each plot and also summarized in Table 3 for all the physical beam-to-column connections.

Table 3 Peak rotations (in rad) in shear-tab beam-to-column connections of the test specimen (locations identified in Figure 7).

\begin{tabular}{|c|c|c|c|}
\hline \multirow{2}{*}{ Test ID } & \multicolumn{3}{|c|}{ Shear-Tab Connections } \\
\cline { 2 - 4 } & "A" & "B" & "C" \\
\hline HS02-25\% & +0.005 & -0.006 & +0.008 \\
\hline HS02-100\% & -0.020 & +0.014 & +0.015 \\
\hline HS02-160\% & -0.026 & +0.023 & -0.025 \\
\hline HS02-200\% & -0.069 & +0.049 & -0.048 \\
\hline
\end{tabular}

The shear-tab connection response in Figure 7 includes the preliminary elastic hybrid simulation HS02-Sine and the test HS02-25\%F. The latter test resulted in higher than expected loading due to issues related to the hybrid simulation and later repeated. The initial low amplitude response of the shear-tab connection was exhibited in these two preliminary tests. Due to the gravity-induced load application on the physical specimen using actuators at the beginning of the hybrid simulation, the moment-rotation relations of the physical shear-tab connections shifted vertically in most cases. This vertical offset was maintained in the measured data to better capture the peak response, though it can result in an offset between the physical and numerical data. Figure 8 shows photos at various damage states that were either taken at the end of the simulation or after the maximum deformation demands occurred thereby directly associating them with the maximum rotation demands indicated in the figures. 
This peer-reviewed published paper appears as: Del Carpio, M.R., Mosqueda, G., Lignos, D.G. (2019). “Experimental Investigation of Steel Building Gravity Framing Systems under Strong Earthquake Shaking", Soil Dynamics and Earthquake Engineering, Vol. 116, pp. 230-241, doi: 10.1016/j.soildyn.2018.10.017

337 The response of the three shear-tab connections (physical and numerical) remained elastic for the 338 first preliminary hybrid simulation conducted with the sine-pulse ground motion, HS02-Sine, as 339 observed in Figure 7 (a). The elastic rotational stiffness of the shear-tab connections A, B, and C were estimated from experimental measurements as $2.0 \times 10^{5}, 3.0 \times 10^{5}$, and $1.3 \times 10^{5} \mathrm{kip}-\mathrm{in} / \mathrm{rad}$, respectively. These values are comparatively larger than the predicted value in the numerical model of $0.4 \times 10^{5} \mathrm{kip}$-in./rad. following the recommendations of Liu and Astaneh-Asl [1]. The first attempted hybrid simulation ( $\mathrm{HS} 02-25 \% \mathrm{~F})$ was not successfully completed with the first story of the physical substructure unexpectedly subjected to a maximum inter-story drift ratio of $1.5 \%$. Figure 7 (b) shows that the measured moment-rotation response exhibited modest inelastic response (with rotations in the order of $0.01 \mathrm{rad}$.) mainly due to friction between the shear-tab plate and the beam web. Also, minor stiffening is observed likely due to bolt bearing. Visual inspection of shear-tab connections identified flaking of white wash indicative of relative movement between the shear-tab plate and beam web.

The successful repeat of the service level earthquake test (HS02-25\%), in Figure 7 (c) demonstrate stable hysteretic response for the shear-tab connections. The energy dissipation due to friction between the shear-tab plate and the beam web was not captured by the numerical substructure of the gravity frame that remained mostly linear. At the MCE intensity (HS02-100\%), a pinched hysteretic response due to bolt bearing was observed. In this case, the numerical model reasonably captured this behavior as well as the peak bending demands of the physical shear-tab connection as seen in Figure 7 (d). Slight yielding of the beam web near the connection was evident for the shear-tab connection A shown in Figure 8(b). Through the MCE level intensity, the shear-tab connections demonstrated ductile behavior governed mainly by (i) friction between the shear-tab plate and beam web and (ii) yielding of the shear-tab plate near the bolt holes and yielding of the beam web for the exterior shear-tab plate in Connection " $\mathrm{A}$ ".

At seismic intensities beyond MCE, significant binding of the lower beam flange on the column flange governed the response of the shear-tab connections. Binding occurred at about 0.02 rads under negative bending in connection " $\mathrm{A}$ " for HS02-160\%. This resulted into an increase of the moment demand within the connection. Binding did not occur in the rest of the shear-tab connections (B and $\mathrm{C}$ ) since these interior connections present typically smaller rotation demands at this level. For HS02-200\%, connection C showed evidence of binding at about -0.02 rads. Connection B was loaded mostly under positive bending with no binding. Evidence of binding is 368 shown for connection A in Figure 7(e,f) and Figure 8(c,d). Binding can lead to plastic hinging in the column and this behavior was not observed during the hybrid simulations. Subsequent pushover tests to failure did show evidence of this behavior [16].

371 Notably, no bolt fracture or shear-tab plate fracture was observed in any of the connections. This 372 is in contrast to the experimental program of Liu and Astaneh-Asl [1] where fracture of bolts and 373 shear-tab plates were typically reported after binding. This is primarily attributed to deeper beams utilized in the testing program by Liu and Astaneh-Asl, and the cumulative damage prior to failure resulting from the standard symmetric loading history. Similar observations regarding differences between loading protocols and seismic testing prior to collapse are discussed in Lignos et al. [9] and Lignos and Krawinkler [18] as well as recently conducted collapse tests on steel columns [3839]. The observed differences in the measured flexural strength of the current testing program and the one conducted by Liu and Astaneh can be attributed to the shallow versus deep beams that were utilized in the two testing programs, respectively [40]. 
This peer-reviewed published paper appears as: Del Carpio, M.R., Mosqueda, G., Lignos, D.G. (2019). "Experimental Investigation of Steel Building Gravity Framing Systems under Strong Earthquake Shaking", Soil Dynamics and Earthquake Engineering, Vol. 116, pp. 230-241, doi: 10.1016/j.soildyn.2018.10.017

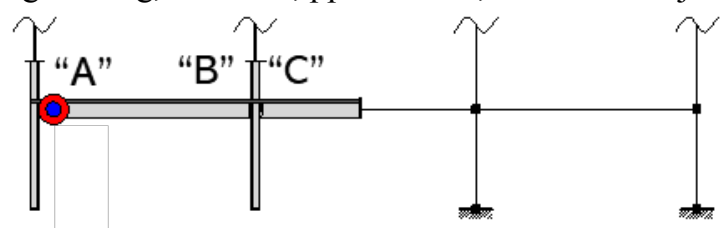

(a) Test ID: HS02-Pulse
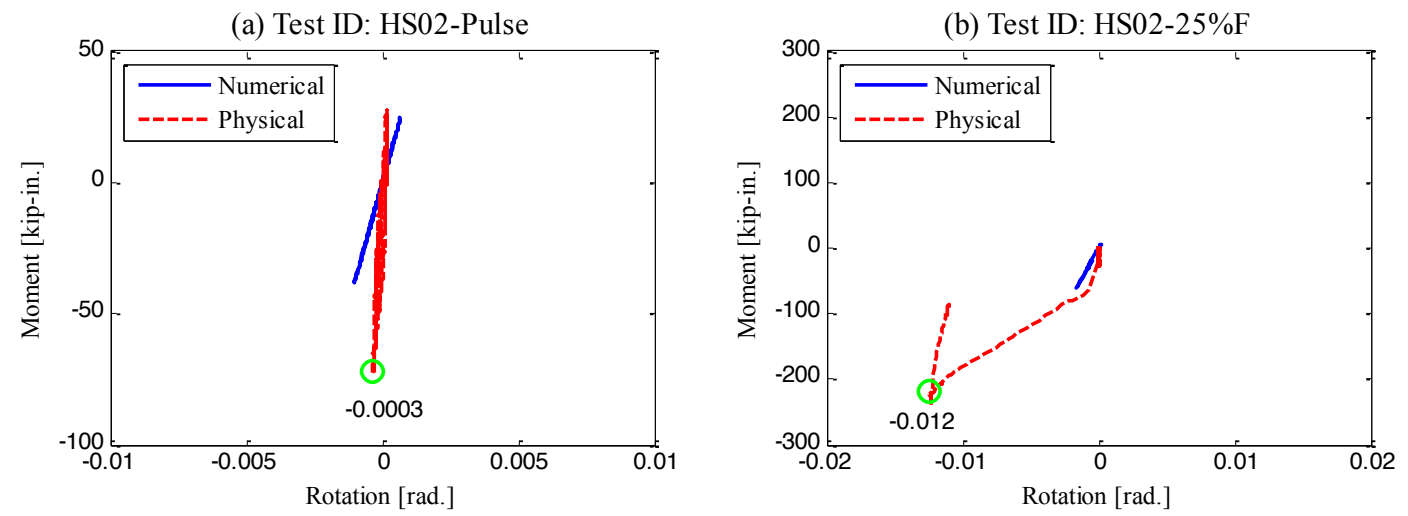

(c) Test ID: HS02-25\%

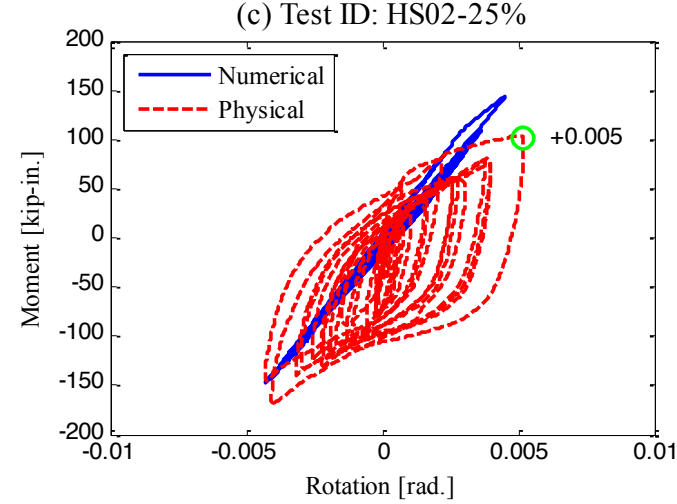

(d) Test ID: HS02-100\%

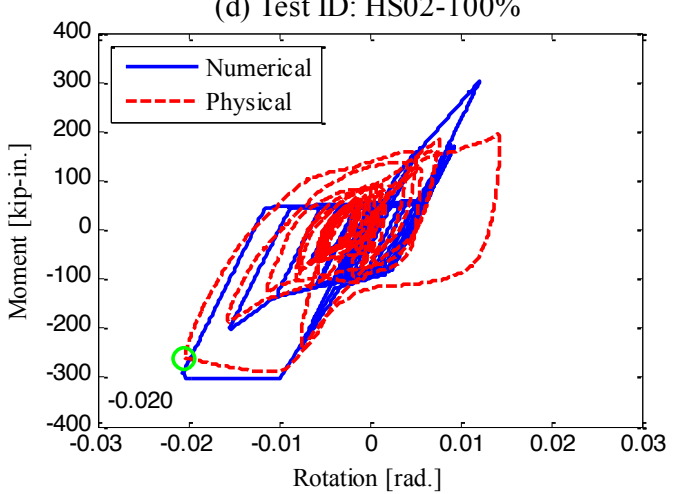

(e) Test ID: HS02-160\%

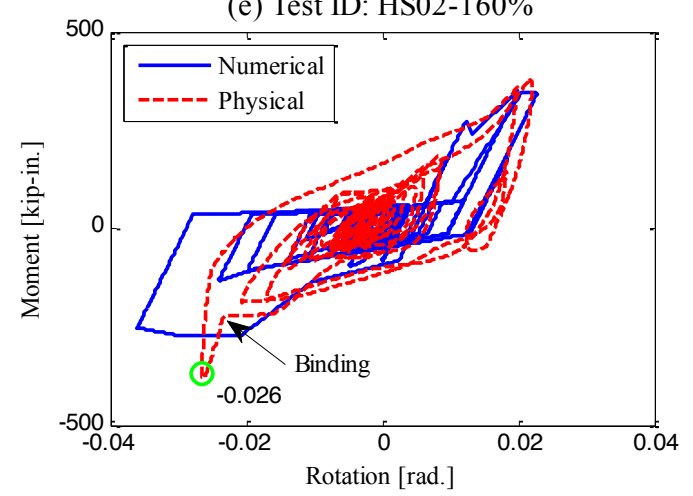

(f) Test ID: HSO2-200\%

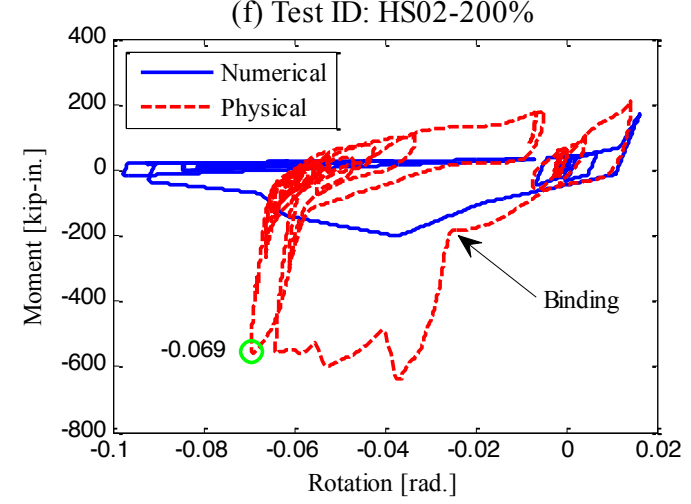

Figure 7 Moment-rotation relations for shear-tab connection "A" 
This peer-reviewed published paper appears as: Del Carpio, M.R., Mosqueda, G., Lignos, D.G. (2019). "Experimental Investigation of Steel Building Gravity Framing Systems under Strong Earthquake Shaking", Soil Dynamics and Earthquake Engineering, Vol. 116, pp. 230-241, doi: 10.1016/j.soildyn.2018.10.017

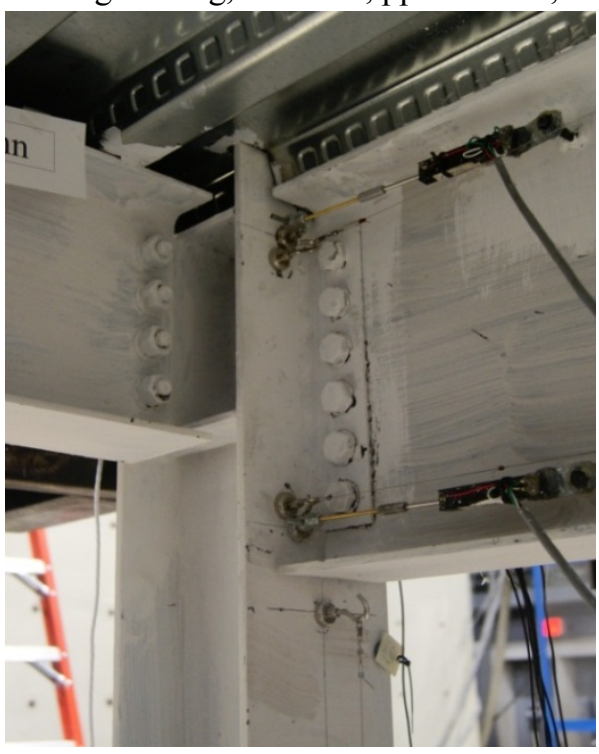

(a) Shear-Tab Conn. "A" [+0.005 rad.], HS02$25 \%$

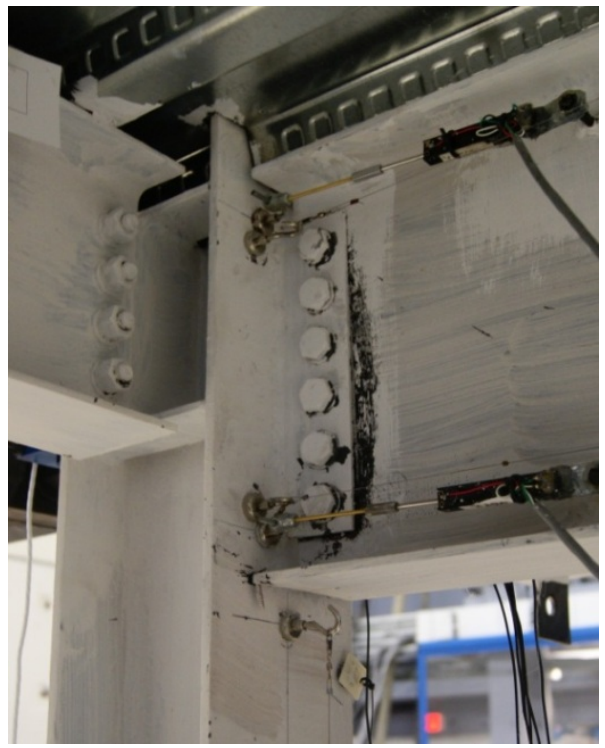

(c) Shear-Tab Conn. "A" [-0.026 rad.], HS02$160 \%$

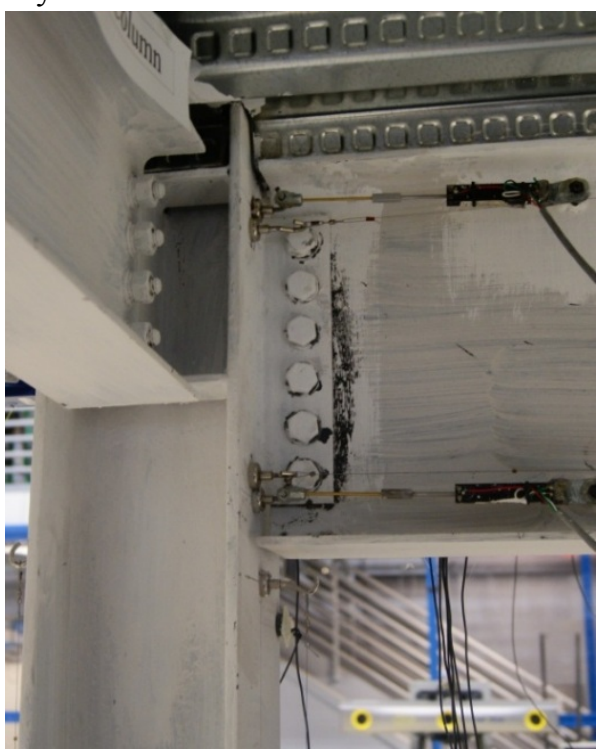

(b) Shear-Tab Conn. "A" [-0.020 rad.], HS02$100 \%$

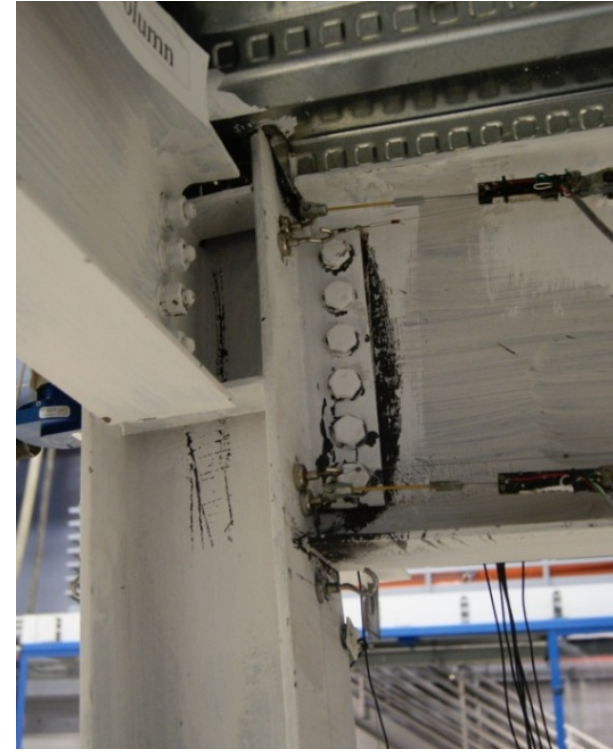

(d) Shear-Tab Conn. "A" [-0.069 rad.], HS02$200 \%$

Figure 8 Photographs of the damage of shear-tab connection "A"

\subsection{Concrete Slab}

385 Damage of the concrete slab was limited to the regions around the columns. Minimal concrete spalling was observed around the interior column as show in Figure 9, while a diagonal crack developed around the east column due to the lateral forces transferred by the horizontal actuator. While there was some evidence of damage on the concrete slab, the concrete floor slab did not lose its vertical load carrying capacity while supporting a dead load. This is worth mentioning 
This peer-reviewed published paper appears as: Del Carpio, M.R., Mosqueda, G., Lignos, D.G. (2019). "Experimental Investigation of Steel Building Gravity Framing Systems under Strong Earthquake Shaking", Soil Dynamics and Earthquake Engineering, Vol. 116, pp. 230-241, doi: 10.1016/j.soildyn.2018.10.017

considering the extend of inelastic damage observed in composite floor systems around the steel columns in typical fully restrained beam-to-column connections [41].

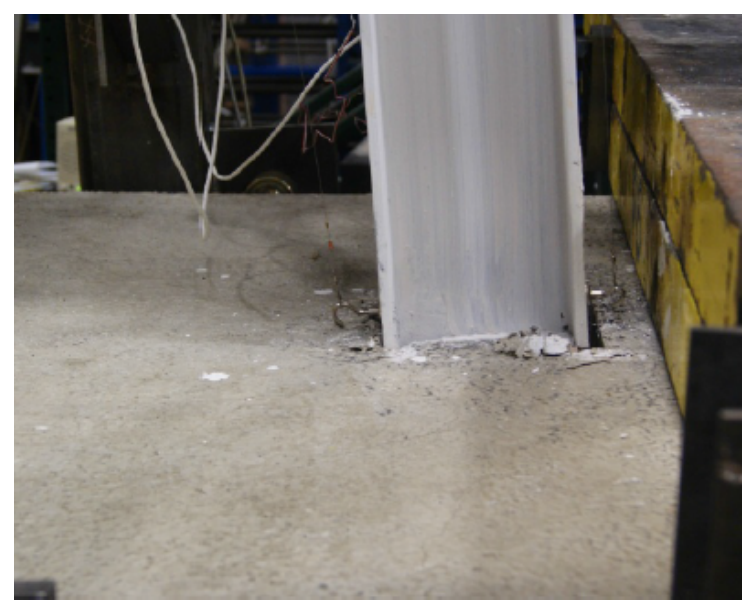

Figure 9 Minor spalling of slab near column after HS02-200\%

\subsection{Steel Columns}

Both columns in the experiment remained essentially elastic through the test series except for the region near the column bases where white wash flaking revealed some flange yielding. The corresponding moment-rotation relations confirmed this observation. While the level of axial forces for the interior and end (exterior) columns due to gravity loading was $13 \%$ and $26 \%$ of the predicted column axial strength (defined as the column cross sectional area times the measured material yield stress), respectively, these minimally increased to $17 \%$ and $27 \%$ at the largest ground motion intensity due to dynamic overturning effects.

During the last hybrid simulation at HS02-200\%, two bolts at each column base plate ( 4 bolts total) fractured in tension as shown in Figure 10. Bolt fracture occurred at a peak first story drift ratio of $3.7 \%$ to $4.7 \%$. The column bases of the physical substructure lost their moment resistance at this point and rocked thereafter. The flexible supports of the numerical substructure (modeled with elastic springs) allowed for yielding at the base of the numerical columns for the last two hybrid simulations (HS01-160\% and HS01-200\%). Therefore, although the flexible supports helped to improve the predictions for low levels of loading, they resulted in unrealistic predictions for large levels of loading in hybrid simulations $\mathrm{HS} 02-160 \%$ and HS02-200\%. Note that elastic deformations are not shown for the numerical model in Figure 10(a). 
This peer-reviewed published paper appears as: Del Carpio, M.R., Mosqueda, G., Lignos, D.G. (2019). "Experimental Investigation of Steel Building Gravity Framing Systems under Strong Earthquake Shaking", Soil Dynamics and Earthquake Engineering, Vol. 116, pp. 230-241, doi: 10.1016/j.soildyn.2018.10.017

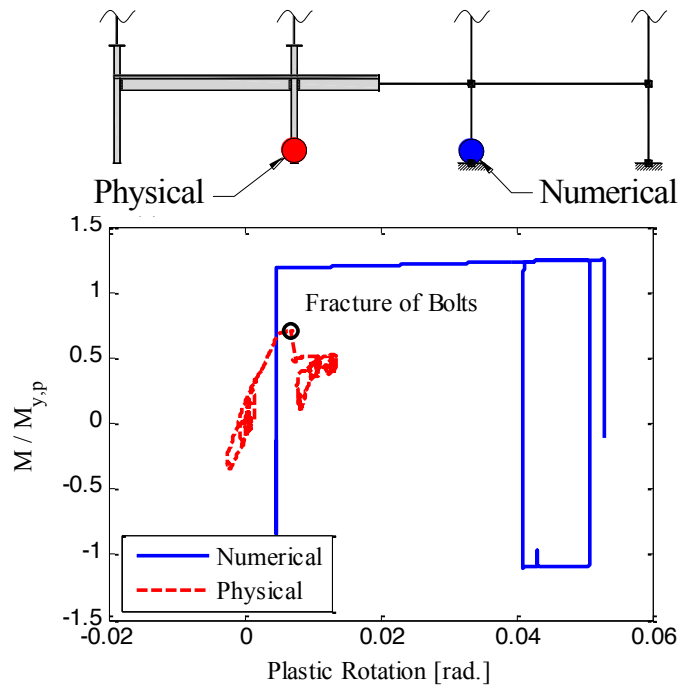

(a) moment-rotation at gravity column base

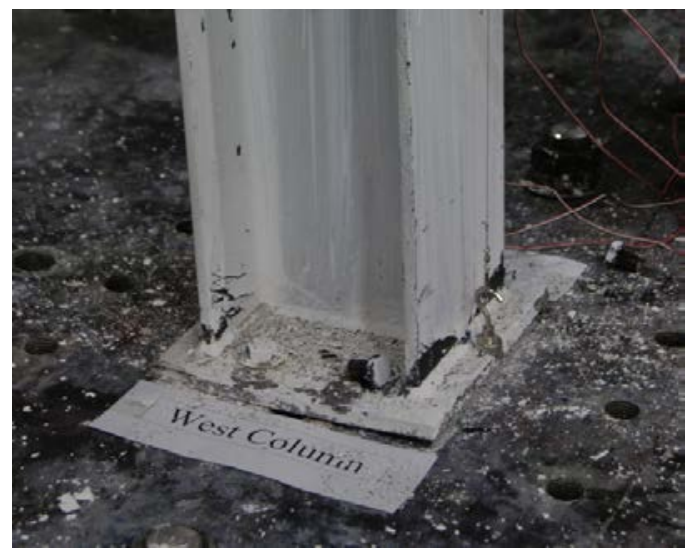

(b) Photograph of damage after test

Figure 10 Response of interior column near base during HS02-200\% test

\subsection{Beam-to-Column Panel Zone Joint}

Visual inspection of the beam-to-column joints showed minor panel zone yielding during the last hybrid simulation at $200 \%$ of the LGPC ground motion (HS02-200\%). This is also evident from white wash flaking shown in Figure 8. Measurements of the panel zone distortion could not be obtained due to the floor beams attached transversely to the panel zone that blocked the vision of the Krypton camera and precluded installation of displacement sensors.

\subsection{Column Base Plates}

A comparison of the base plate response of the exterior physical and numerical columns shows a similar linear response up to the HS02-25\% test as shown in Figure 11(a). This is expected because the elastic stiffness of the numerical model was calibrated before the test. However, the response of the physical column base plate support during hybrid simulation HS02-100\% shown in Figure 11(b) resembles a self-centering hysteretic response as a result of rocking at the base of the gravity columns. The column base plate, initially straight, bended and adopted a rounded convex shape upon cyclic loading and consequently flatten the flag-type hysteretic response. Fracture of the first bolt at the physical column occurred at a rotation of approximately $0.03 \mathrm{rad}$. Fracture of the second bolt moved the LEDs of the Krypton system and did not allow for capturing the subsequent column base response. 
This peer-reviewed published paper appears as: Del Carpio, M.R., Mosqueda, G., Lignos, D.G. (2019). "Experimental Investigation of Steel Building Gravity Framing Systems under Strong Earthquake Shaking", Soil Dynamics and Earthquake Engineering, Vol. 116, pp. 230-241, doi: 10.1016/j.soildyn.2018.10.017

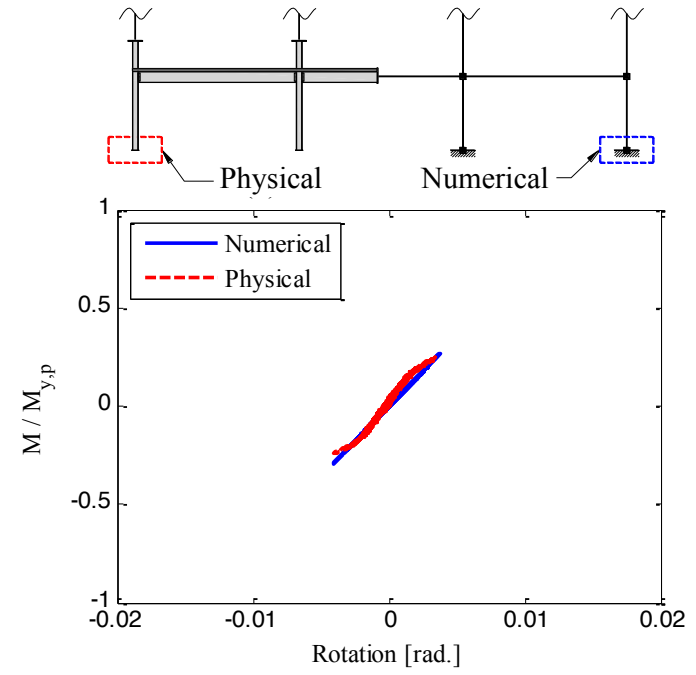

(a) HS02-25\% test

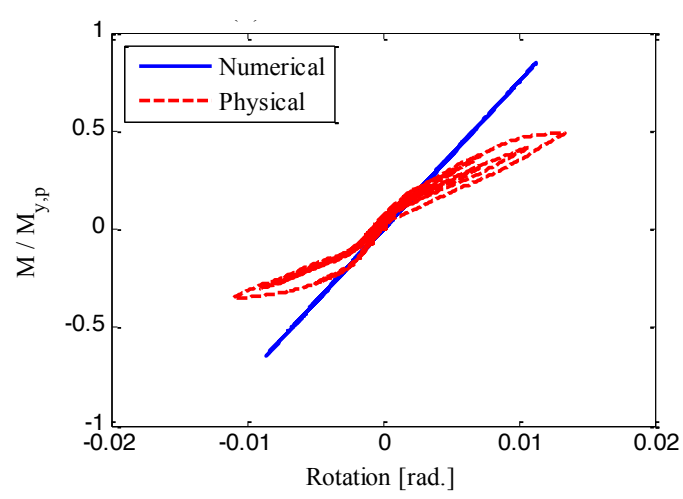

(b) HS02-100\% test

Figure 11 Deduced moment-rotation relations for column base plate

\section{7}

438

439

440

441

442

443

444

445

446

447

448

449

450

451

452

453

454

\subsection{Subassembly Base Shear Force}

Figure 12 presents the first story base shear vs the first story drift ratio for the physical and the equivalent numerical model. The base shear values were obtained by summing the column shear forces obtained from column end moments. The base shear is normalized by one third of the total seismic weight of the half-scale building to represent the base shear of all gravity frames. The peak normalized base shear is about 0.14 for the gravity framing while the normalized base shear force of the steel MRF is 0.2 [11]. It can be seen in Figure 10(a) that the elastic flexibility of both the physical and numerical model is similar. However, for large levels of loading, the numerical substructure slightly over-predicts the lateral yield strength of the physical model. This was partly attributed to the elastic springs at the base of the columns used to simulate the flexibility of the supports that eventually led to yielding at the base of the columns. The experimental findings suggest that the contribution of the gravity framing to the lateral load resistance and strength of a steel frame building is not insignificant. In particular, the normalized design base shear is 0.08 [18] for the tested steel frame building. Therefore, the corresponding overstrength factor $\Omega=0.34 / 0.08$ $=4.25$ in this case. This value is somewhat larger than those presented in ASCE 7-16 [42] for steel frame buildings with special moment frames but fairly consistent with those presented in Elkady and Lignos [43] based on extensive nonlinear building simulations of steel frame buildings with special moment frames. 
This peer-reviewed published paper appears as: Del Carpio, M.R., Mosqueda, G., Lignos, D.G. (2019). "Experimental Investigation of Steel Building Gravity Framing Systems under Strong Earthquake Shaking", Soil Dynamics and Earthquake Engineering, Vol. 116, pp. 230-241, doi: 10.1016/j.soildyn.2018.10.017
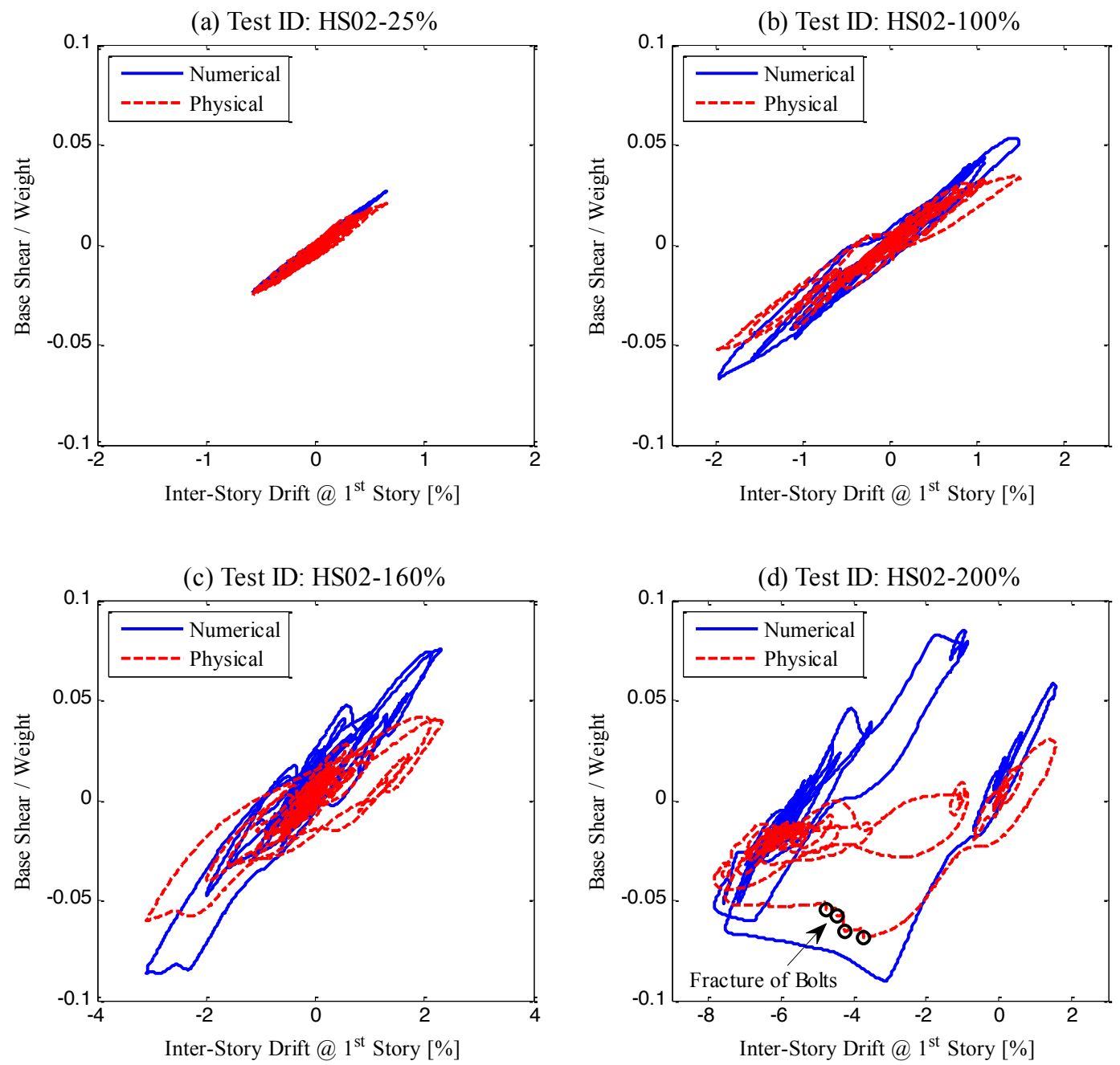

\section{Figure 12 Normalized Base Shear vs first story drift for experimental and numerical gravity frame substructures}

\section{SUMMARY AND CONCLUSIONS}

459 A $1 \frac{1}{2}$-bay by $1 \frac{1}{2}$-story subassembly of a steel moment-resisting frame with concrete floor slab was tested via hybrid simulation with substructuring. The $1 / 2$-scale physical model was subjected to large story drifts (i.e., 16.4\% at the first story) to observe its seismic behavior near collapse. The large subassembly allowed for the systematic documentation of the hysteretic behavior of various components of the gravity framing including the steel beams, columns, the panel zone, the column bases and their interaction with neighboring members under realistic combinations of lateral and axial loads. These tests thus represent an improvement to traditional cyclic tests on cruciform or T-shaped subassemblies as a step towards better characterizing system-level response. The data obtained from these tests demonstrate that hybrid simulation can be a cost-effective tool for assessing the seismic behavior of moment frames near collapse. The capabilities of numerical models to trace the response of the above mentioned components were also assessed using the data obtained from the experiments. The key conclusions of the paper are summarized as follows: 
This peer-reviewed published paper appears as: Del Carpio, M.R., Mosqueda, G., Lignos, D.G. (2019). "Experimental Investigation of Steel Building Gravity Framing Systems under Strong Earthquake Shaking", Soil Dynamics and Earthquake Engineering, Vol. 116, pp. 230-241, doi: 10.1016/j.soildyn.2018.10.017

- The elastic stiffness of the gravity framing connections during service level shaking was at least twice larger than what is recommended in ASCE 41-17 [44] for partially restrained beam-to-column connections. Such differences diminished at higher ground motion intensities when the connections exhibited considerable inelastic behavior.

- Beam binding to the gravity column face at relatively small rotation demands (0.02 rads) did not cause bolt and shear tab fracture of any of the gravity framing connections. This contradicts findings from conventional shear tab connection tests [1](Liu and Astaneh 2000). This is attributed to differences in the respective beam depths between testing programs (shallow versus deep) as well as the inelastic cumulative damage arising from symmetric loading protocols.

- Cosmetic damage was observed in the concrete slab, the steel columns and the beam-tocolumn joint panel zones of the physical substructure. This is worth noting considering the extent of inelastic damage observed in composite floor beams that are part of fully restrained beam-to-column connections.

- The gravity column base connections experienced considerable inelastic damage involving steel plate yielding and anchor rod fracture at seismic intensities associated with a maximum considered earthquake. The column base connection rocked at higher intensities exhibiting a favorable hysteretic behavior with self-centering characteristics.

- The corresponding overstrength of the combined steel MRF and gravity framing systems was more than 4, which is somewhat larger than the values reported in ASCE 7-16 [42], but consistent with prior studies that assessed the influence of the gravity framing system on the system behavior factors in steel frame buildings with special moment frames.

- Although numerical models representing the gravity framing components estimate in a dissent manner the global engineering demand parameters (story drift ratios and story shear forces) of the gravity framing system, they should be properly refined to predict local engineering parameters if these are of interest.

\section{ACKNOWLEDGMENTS}

This work was primarily supported by the National Science Foundation (NSF) under grant CMMI0748111 with additional support from the NEES equipment at the University at Buffalo supported by NSF award CMS-0402490. This support is gratefully acknowledged. Any opinions, findings, and conclusion or recommendation expressed in this paper are those of the authors and do not necessarily reflect the views of the sponsor. The authors thank the laboratory personnel at University at Buffalo for their technical support and guidance during the design and construction of the experimental setup.

\section{REFERENCES}

1. Liu, J. and A. Astaneh-Asl (2000). "Cyclic Testing of Simple Connections including Effects of Slab.” J. Struct. Eng., 126(1): 32-39.

2. Weigand, J.M. and Berman, J.W. (2016) "Steel gravity connectionss subjected to large rotations and axial loads" Proceedings of the Eighth International Workshop on Connection in Steel Structures, Boston, MA. 
This peer-reviewed published paper appears as: Del Carpio, M.R., Mosqueda, G., Lignos, D.G. (2019). "Experimental Investigation of Steel Building Gravity Framing Systems under Strong Earthquake Shaking", Soil Dynamics and Earthquake Engineering, Vol. 116, pp. 230-241, doi: 10.1016/j.soildyn.2018.10.017

3. Béland T. et al., (2018). "Contribution of Beam-Column Connections with Bolted Angles in the Reserve Capacity and Full-Scale Cyclic Testing", Key Engineering Materials, 763:475484.

4. Gupta, A. and Krawinkler, H. (2000). "Behavior of Ductile SMRFs at various Seismic Hazard Levels.” J. Struct. Eng, 126(1): 98-107.

5. Flores F.X., Charney F.A. and Lopez-Garcia D. (2014). "Influence of the gravity framing system on the collapse performance of special steel moment frames." J. Constructional Steel Research, 101: 351-362.

6. Elkady, A., Lignos, D. G. (2015). "Effect of Gravity Framing on the Overstrength and Collapse Capacity of Steel Frame Buildings with Perimeter Special Moment Frames”, Earthquake Eng. Struct. Dyn., 44(8), 1289-1307.

7. Federal Emergency Management Agency (FEMA). (2000). State of the Art Report on Connection Performance (FEMA 355D), Washington, D.C.

8. Krawinkler, H., Gupta, A., Medina, R., and Luco, N. (2000). "Development of Loading Histories for Testing of Steel Beam-to-Column Assemblies." SAC Background Report, $\mathrm{SAC} / \mathrm{BD}-00 / 10$.

9. Lignos, D. G., Krawinkler, H., and Whittaker, A. S. (2011a). "Prediction and validation of sidesway collapse of two scale models of a 4-story steel moment frame." Earthquake Eng. Struct. Dyn., 40(7), 807-825.

10. Lignos, D. G., Hikino, T., Matsuoka, Y., and Nakashima, M. (2013). "Collapse Assessment of Steel Moment Frames Based on E-Defense Full-Scale Shake Table Collapse Tests." J. Struct. Eng., 139(1), 120-132.

11. Del Carpio, M., Mosqueda, G. and Lignos, D. (2016). "Seismic performance of a steel moment frame subassembly tested from the onset of damage through collapse." Earthquake Eng. Struct. Dyn., 45(10):1563-1580.

12. Mahmoud, H., Elnashai, A., Spencer, B., Jr., Kwon, O., and Bennier, D. (2013). "Hybrid Simulation for Earthquake Response of Semirigid Partial-Strength Steel Frames." J. Struct. Eng., 139, Special Issue: NEES 1: Advances in Earthquake Eng., 1134-1148.

13. Wang, T., Mosqueda, G., Jacobsen, A., and Delgado, M. C. (2012). "Performance Evaluation of a Distributed Hybrid Test Framework to Reproduce the Collapse Behaviour of a Structure." Earthquake Eng. Struct. Dyn., 41(2), 295-313.

14. Schellenberg, A. H., Huang, Y., and Mahin, S. A. (2008). "Structural FE-Software Coupling through the Experimental Software Framework, OpenFresco." Proc. 14 ${ }^{\text {th }}$ World Conf. Earthquake Eng., Beijing, China.

15. Hashemi, M. J., and Mosqueda, G. (2014). "Innovative Substructuring Technique for Hybrid Simulation of Multi-Story Building through Collapse." Earthquake Eng. Struct. Dyn., 43(14), 2059-2074.

16. Del Carpio R., M., Mosqueda, G., and Lignos, D. G. (2014). "Hybrid Simulation of the Seismic Response of a Steel Moment Frame Building Structure through Collapse." Technical Report MCEER-14-0003, State University of New York at Buffalo, NY. 
This peer-reviewed published paper appears as: Del Carpio, M.R., Mosqueda, G., Lignos, D.G. (2019). "Experimental Investigation of Steel Building Gravity Framing Systems under Strong Earthquake Shaking", Soil Dynamics and Earthquake Engineering, Vol. 116, pp. 230-241, doi: 10.1016/j.soildyn.2018.10.017

17. Del Carpio R., M., Mosqueda, G., and Hashemi, M. J. (2015). "Large-Scale Hybrid Simulation of a Steel Moment Frame Building Structure through Collapse." J. Struct. Eng., DOI: 10.1061/(ASCE)ST.1943-541X.0001328.

18. Lignos, D. G., and Krawinkler, H. (2012). "Sidesway Collapse of Deteriorating Structural Systems under Seismic Excitations." Rep. No. TB 172, The John A. Blume Earthquake Engineering Research Center, Stanford University, CA.

19. International Building Code (IBC) (2003). International Code Council, Birmingham, AL.

20. American Institute of Steel Construction (AISC). (2010). Seismic Provisions for Structural Steel Buildings, including Supplement No. 1, Chicago.

21. American Society of Civil Engineers (ASCE). (2002). Minimum Design Loads for Buildings and Other Structures (SEI/ASCE-02), Virginia.

22. McKenna, F., Fenves, G. L., Scott, M. H. (2000). Open system for earthquake engineering simulation. University of California, Berkeley, CA..

23. Open Framework for Experimental Setup and Control (OpenFresco). (2008). Pacific Earthquake Engineering Research Center (PEER), (http://openfresco.berkeley.edu).

24. Hashemi, M.J., Mosqueda, G., Lignos, D., Medina, R., and Miranda, E. (2016). "Assessment of Numerical and Experimental Errors in Hybrid Simulation of Framed Structural Systems through Collapse.” J. of Earthquake Eng., 20(6):885-909.

25. Del Carpio, M., Hashemi, M.J. and Mosqueda, G. (2017) "Evaluation of integration methods for hybrid simulation of complex structural systems through collapse." Earthquake Eng. and Eng. Vibration, 16:745-759.

26. Moncarz, P. D., and Krawinkler, H. (1981). "Theory and Application of Experimental Model Analysis in Earthquake Engineering." Rep. No. 50, The John A. Blume Earthquake Engineering Research Center; Stanford University, CA.

27. American Institute of Steel Construction (AISC). (2016). Seismic Provisions for Structural Steel Buildings, ANSI/AISC 341-16. Chicago.

28. Lignos, D. G., and Krawinkler, H.(2011). "Deterioration Modeling of Steel Components in Support of Collapse Prediction of Steel Moment Frames under Earthquake Loading." J. Struct. Eng. 137(11), 1291-1302.

29. Kanavinde, A.M., Grilli, D.A. and Zareian, F. (2012). "Rotational Stiffness of Exposed Column Base Connections: Experiments and Analytical Models.” J. Struct. Eng. 138(5): 549560 .

30. Lowes, L. and Altoontash, A. (2003). "Modeling Reinforced-Concrete Beam-Column Joints subjected to Cyclic Loading.” J. Struct. Eng, 129(12):1686-1697.

31. Mitra, N. (2007). “An Analytical Study of Reinforced Concrete Beam-Column Joint Behavior under Seismic Loading.” PhD Dissertation, University of Washintong, WA.

32. Zareian, F., and Medina, R. A. (2010). "A Practical Method for Proper Modeling of Structural Damping in Inelastic Plane Structural Systems." Computers and Structures, 88(1-2), 45-53.

33. Newmark, N. M. (1959). “A Method of Computation for Structural Dynamics.” J. Eng. Mech., 67. 
This peer-reviewed published paper appears as: Del Carpio, M.R., Mosqueda, G., Lignos, D.G. (2019). "Experimental Investigation of Steel Building Gravity Framing Systems under Strong Earthquake Shaking", Soil Dynamics and Earthquake Engineering, Vol. 116, pp. 230-241, doi: 10.1016/j.soildyn.2018.10.017

34. Dorka, U. E., and Heiland, D. (1991). "Fast Online Earthquake utilizing a Novel PC Supported Measurement and Control Concept." 4th Conf. on Struct. Dyn., Southampton, UK.

35. Shing, P. S. B., Vannan, M. T., and Cater, E. (1991). "Implicit Time Integration for Pseudodynamic Tests." Earthquake Eng. Struct. Dyn., 20(6), 551-576.

36. Schellenberg, A. H., Mahin, S. A., and Fenves, G. L. (2009). "Advanced Implementation of Hybrid Simulation." Rep. PEER 2009/104. University of California, Berkeley, CA.

37. Ruiz-García, J., and Miranda, E. (2006). "Evaluation of Residual Drift Demands in Regular Multi-Storey Frames for Performance-Based Seismic Assessment." Earthquake Engng. Struct. Dyn., 35(13): 1609-1629.

38. Suzuki, Y., Lignos, D.G. (2015). "Large Scale Collapse Experiments of Wide Flange Steel Beam-Columns." Proc., $8^{\text {th }}$ International Conference on Behaviour of Steel Structures in Seismic Areas, Shanghai, China, July 1-4, 2015.

39. Elkady, A., and Lignos, D.G. (2018). "Full-Scale Testing of Deep Wide-Flange Steel Columns under Multiaxis Cyclic Loading: Loading Sequence, Boundary Effects, and Lateral Stability Bracing Force Demands.” J. Struct. Eng., 139(2), 04017189.

40. ElJisr, H., and Lignos, D.G. (2018). "Composite Beam Effects and Implications to Seismic Design Provisions." Proceedings, $16^{\text {th }}$ European Conference on Earthquake Engineering (16ECEE), Thessaloniki, Greece, 18-21 June 2018.

41. Zhang, X., and Ricles, J. (2006)."Experimental Evaluation of Reduced Beam Section Connections to Deep Columns." J. Struct. Eng.,132(3), 346-357.

42. American Society of Civil Engineers (ASCE). (2017). Minimum Design Loads and Associated Criteria for Buildings and Other Structures. ASCE/SEI 7-16), Virginia.

613 43. Elkady A., and Lignos, D. G. (2015). "Effect of gravity framing on the overstrength and Eng. Struct. Dyn., 44(8), 1289-1307.

44. American Society of Civil Engineers (ASCE). (2017). Seismic Evaluation and Retrofit of Existing Buildings. ASCE/SEI 41-17), Virginia. 